\title{
hCAR-EGFP fusion receptor in human follicular lymphoma B cells - A model for adenoviral gene therapy for B cell malignancies
}

\author{
MIKKO MÄTTÖ ${ }^{*}$, ULLA-MAIJA NUUTINEN ${ }^{1 *}$, TANJA HAKKARAINEN ${ }^{2,5}$, \\ TIZIANO TALLONE ${ }^{3}$, JARMO WAHLFORS ${ }^{2}$ and JUKKA PELKONEN ${ }^{1,4}$
}

\begin{abstract}
${ }^{1}$ Department of Clinical Microbiology, University of Kuopio, Harjulantie $1 \mathrm{C} ;{ }^{2}$ Department of Biotechnology and Molecular Medicine, A.I. Virtanen Institute for Molecular Sciences, University of Kuopio, Neulaniementie 2, FIN-70210 Kuopio, Finland; ${ }^{3}$ PolyGene AG, Riedmattstrasse 9, CH-8153 Rümlang, Switzerland; ${ }^{4}$ Department of Clinical Microbiology, Kuopio University Hospital, Puijonlaaksontie 2, FIN-70210 Kuopio, Finland
\end{abstract}

Received December 23, 2005; Accepted February 7, 2006

\begin{abstract}
Adenovirus-mediated gene therapy for hematopoietic malignancies, especially those derived from B cells, is difficult due to systemic nature of these diseases. More importantly, most tumor cells derived from B cell lineage express a very low level of the adenovirus receptor hCAR; thus, warranting the design of adenoviral vectors with high affinity to abundant B cell surface molecules. To mimic this approach and to test the validity of adenoviral vectors in gene therapy of disseminated malignancies, we created an hCARexpressing follicular lymphoma B cell line. The cell line was generated with the aid of a lentivirus vector carrying a novel fusion gene with EGFP replacing the cytoplasmic domain of hCAR. After verifying that this cell line was expressing the hybrid receptor in a correct manner and enrichment of the bright EGFP positive population, the cells were transduced with adenoviruses expressing the red fluorescent protein DsRed2. It was shown that regular transduction with a low viral dose (1 pfu/cell) increased the gene transfer rate by a factor of 5. Furthermore, experiments with adenovirus vector carrying the HSV-TK-GFP transgene demonstrated that the modified follicular lymphoma B cells became sensitive to
\end{abstract}

Correspondence to: Dr Mikko Mättö, Department of Clinical Microbiology, University of Kuopio, Harjulantie 1 C, FIN-70210 Kuopio, Finland

E-mail:mikko.matto@uku.fi

Present address: ${ }^{5}$ Cancer Gene Therapy Group, Rational Drug Design, University of Helsinki and Department of Oncology, Helsinki University Central Hospital, Helsinki, Finland

${ }^{*}$ Contributed equally

Key words: hCAR, EGFP, fusion gene, lentiviral vectors, transduction, B cell and human ganciclovir while the parental cells remained virtually resistant to this form of gene therapy. In summary, we show here with this simple model system that adenoviral gene therapy of B cell malignancies is possible provided that correct receptors for adenovirus attachment are present on the surface of the target cells. Thus, our results warrant further modifications of adenovirus capsid to obtain vectors with specific affinity to B cell epitopes.

\section{Introduction}

It is known that treatment of B cell malignancies with conventional chemotherapy could still be more efficient (1-4). In order to increase the treatment efficacy of B cell malignancies, development of new therapies is needed. One of the enhanced therapy strategies could be cell type-specific gene therapy. Human B cells are known to be resistant to conventional nonviral gene transfer methods, but there are reports of successful virus-mediated gene delivery into B cells using adenovirus, Epstein-Barr virus (EBV), adeno-associated virus (AAV) or lentivirus vectors (5-10). Using B cell-targeted virus-mediated gene therapy, B cell-derived cancers could be treated more efficiently since all B cells can be killed and even then the patient survive under IgG-replacement therapy, such as shown in X-linked agammaglobulinemia patients (11). The treatment of B cell malignancies with targeted adenoviruses would be an interesting option due to many advantageous features of this vector type (12). However, it is known that adenoviruses transduce B cells poorly owing to lack of expression of the adenovirus attachment receptor hCAR (human coxsackie adenovirus receptor). Thus, adenovirus vectors need extensive capsid modifications to be useful in B cell gene transfer. This would increase efficiency, specificity and reduce the well-known side-effects occurring due to natural adenovirus tropism to liver cells $(13,14)$. Potential and strictly B cell-specific surface structures could be $\operatorname{Ig} \alpha$ and $\operatorname{Ig} \beta$ that are members of the $B$ cell receptor (BCR) complex. Furthermore, BCR-specific adenoviruses could be achieved by creating a fusion protein from anti-BCR antibody 
(Ab) and hCAR ectodomain protein further linked to adenovirus capsid, as previously described with CD40 and CAR ectodomain $(15,16)$. In addition, BCR complex targeting is advantageous because BCR-antigen complexes are internalized using clathrin-coated pit endocytosis, as occurs with a natural adenovirus receptor complex $(17,18)$.

As a model of B cell targeted and specific adenoviral gene therapy, we used a novel fusion gene in which the cytoplasmic tail of hCAR was replaced with marker protein EGFP. The hCAR-EGFP fusion gene construct was introduced to hCAR negative human follicular B cell lymphoma cells using lentiviral gene transfer method (19). In this experimental model we could show indirectly that adenovirus retargeting can change adenovirus resistant cells to become sensitive, suggesting that adenoviral gene therapy of B cell malignancies is feasible, but further development of appropriately targeted adenovirus vectors is warranted to increase the specificity and efficacy.

\section{Materials and methods}

The follicular lymphoma cell line HF28RA has been described earlier (20). The cells were cultured in a moist atmosphere of $5 \% \mathrm{CO}_{2}$ at $37^{\circ} \mathrm{C}$. RPMI-1640 medium was used as a growth medium (Gibco BRL Life Sciences, Paisley, Scotland) supplemented with $5 \%$ heat-inactivated fetal calf serum (FCS, Biological Industries, Kibbuz Beit Haemek, Israel), $2 \mathrm{mM}$ L-glutamine, $200 \mu \mathrm{g} / \mathrm{ml}$ streptomycin (SigmaAldrich, Stenheim, Germany), $240 \mathrm{IU} / \mathrm{ml}$ penicillin (Orion, Espoo, Finland), $10 \mathrm{mM}$ HEPES buffer (Gibco BRL), $0.1 \mathrm{mM}$ nonessential amino acids (Gibco BRL), $1.0 \mathrm{mM}$ sodium pyruvate (Gibco BRL), and $20 \mu \mathrm{M}$ 2-mercaptoethanol (Fluka Chemie, Buch, Switzerland).

Expression of fluorescent proteins: hCAR-EGFP, DsRed2 (red fluorescent protein from Discosoma sp.) and TK-GFP (herpes simplex virus type I thymidine kinase and green fluorescent protein), was detected using FACScan and FACSCalibur (BD Biosciences, San Jose, CA, USA). Cells expressing hCAR-EGFP fusion gene were further enriched and purified by cell sorting using EPICS Elite ESP flow cytometer (Beckman Coulter, Fullerton, CA, USA). The cell surface expression of hCAR was detected with hCAR-specific anti-hCAR mAb (RmcB, mouse anti-human monoclonal $\mathrm{Ab}$ ) (21) and Tri-color conjugated goat anti-mouse Ab (Caltag Laboratories, Burlingame, CA, USA).

Truncated hCAR ( $\triangle \mathrm{hCAR})$ without the cytoplasmic domain was amplified from a plasmid, pBluescriptSK(+)hCAR(1-262), by PCR with primers that contained overhanging BamHI and Sal I cleavage sites. The primers for hCAR PCR were: hCAR sense (S) 5'-AAA GGA TCC GGC AGC CAC CAT GGC GCT CC-3' and hCAR anti-sense (AS) 5'-AAA GTC GAC CTT TTT ACG ACA GCA AAA GAT G-3'. The EGFP lacking the ATG start codon ( $\triangle \mathrm{EGFP}$ ) was amplified by PCR from a plasmid, pEGFP-C3, using primers that contained overhanging SalI and HindIII cleavage sites. The primers for EGFP PCR were: EGFP (S) 5'-AAA GTC GAC GTG AGC AAG GGC GAG GAG CTG TT-3' and EGFP (AS) 5'-AAA AAG CTT CTA CTT GTA CAG CTC GTC CAT GCC G-3'. $\triangle$ hCAR was further subcloned into a BamHI-SalI-digested pGEM3Z-plasmid, and fusion gene
hCAR-EGFP was created by subcloning $\triangle E G F P$ into a SalIHindIII-digested hCAR-pGEM3Z. The plasmid containing hCAR-EGFP was subcloned into the BamHI-HindIII-digested pSCT1, derived from the eukaryotic expression vector pSTC (22). The hCAR-EGFP was further cloned into the BamHIKpnI-digested pHRCMV plasmid (23). Finally, the lentiviral vector containing the fusion gene hCAR-EGFP was produced following the protocol described earlier (19). The titer of produced hCAR-EGFP lentivirus was $5 \times 10^{6}$ t.u. (transducing units $/ \mathrm{ml}$ as measured by FACS analysis (19).

First generation E1/E3 deleted serotype 5 AdDsRed2 vector (adenovirus vector containing red fluorescent protein DsRed2) was created by inserting BglII-NotI-digested DsRed2 fragment from pDsRed2-N1 (BD Biosciences Clontech, Mountain View, CA, USA) into pShuttleCMV (AdEasy-kit ${ }^{\mathrm{TM}}$, Qbiogene, Illkirch, France), further to obtain pShuttleDsRed2. PmeIlinearized pShuttleDsRed 2 and circular pAdEasy-1 were cotransfected into E. coli strain BJ5183 cells followed by homologous recombination to obtain pAdDsRed2 (Adenoviral plasmid). PacI-linearized pAdDsRed2 was transfected into 293 cells, CRL-1573 (ATCC, Manassas, VA, USA) with Superfect (Qiagen, Hilden, Germany) following the manufacturer's instructions. Adenovirus colonies were picked and virus was propagated in 293 cells and purified using standard techniques. Viral particles (VP) were determined with spectrophotometry and plaque forming units (pfu) with plaque assay. AdTK-GFP vector (adenovirus vector containing TK-GFP fusion gene) was constructed earlier (24). Titers of viruses used were: AdDsRed2: $5.0 \times 10^{11} \mathrm{VP} / \mathrm{ml} ; 3.28 \times 10^{10} \mathrm{pfu} / \mathrm{ml}$, and for AdTKGFP: $4.2 \times 10^{11} \mathrm{VP} / \mathrm{ml} ; 2.2 \times 10^{10} \mathrm{pfu} / \mathrm{ml}$.

The HF28RA cells were transduced with hCAR-EGFP lentivirus in a 6-well plate using $100,000 \mathrm{cells} / \mathrm{ml} / \mathrm{well}$, in the presence of polybrene $8 \mu \mathrm{g} / \mathrm{ml}$ (Sigma-Aldrich, Stenheim, Germany) and with 1.5 t.u./cell. Adenoviral transductions with AdDsRed2 or AdTK-GFP vector (both with 1, 10 and $100 \mathrm{pfu} / \mathrm{cell}$ ), were done according to the following protocol: $1 \times 10^{6}$ cells were added onto a 24 -well plate in $300 \mu 1$ of serumfree growth medium containing adenovirus and incubated at $37^{\circ} \mathrm{C}$ for $3 \mathrm{~h}$. After transduction, $1 \mathrm{ml}$ of complete growth medium was added to the wells and incubation was continued at $37^{\circ} \mathrm{C}$ for $24-48 \mathrm{~h}$ before analysis of DsRed2 or TK-GFP expression.

Total mRNA was isolated from $10^{6}$ cells of each sample, using a MasterPure ${ }^{\mathrm{TM}}$ kit (Epicentre, Madison, WI, USA). DNase I and Proteinase K treatments were included in the total mRNA isolation procedures. cDNA was synthesized as described earlier (25) and stored at $-20^{\circ} \mathrm{C}$. Expression of TK and $\mathrm{B} 2 \mu \mathrm{G}$ was analyzed by RT-PCR using primers described earlier $(26,27)$. RT-PCR was performed with the following cycling parameters: $3 \mathrm{~min}$ at $94^{\circ} \mathrm{C}$ followed by 34 cycles of $1 \mathrm{~min}$ at $94^{\circ} \mathrm{C}, 1 \mathrm{~min}$ at $57^{\circ} \mathrm{C}$ and $1 \mathrm{~min}$ at $72^{\circ} \mathrm{C}$ with a final 10 min extension at $72^{\circ} \mathrm{C}$. Specific RT-PCR products were visualized and analyzed after agarose gel (1.3\% agarose) electrophoresis.

Cell viability was analyzed with MTT-assay according to manufacturer's instructions (Cell proliferation kit II, Roche Diagnostics, Indianapolis, IN, USA). In brief, the cells were plated onto a 96-well plate at the density of 40,000 cells/well followed by infection with AdTK-GFP for $6 \mathrm{~h}$ at $37^{\circ} \mathrm{C}$ using 1,10 and $100 \mathrm{pfu} / \mathrm{cell}$. After infection, fresh growth media 


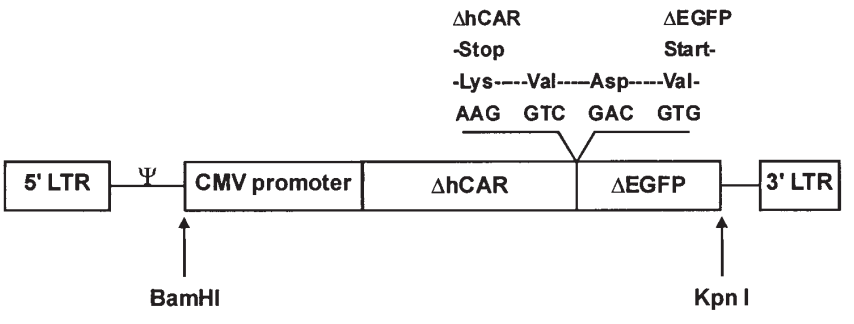

Figure 1. The schematic presentation of the hCAR-EGFP lentiviral vector. The hCAR-EGFP lentiviral vector contains 5' and 3' LTRs (long terminal repeats), $\Psi$ (packaging signal), CMV promoter (human cytomegalovirus promoter), $\triangle$ hCAR (human coxsackie adenovirus receptor without the cytoplasmic tail and stop codon) and $\triangle E$ EFP (enhanced green fluorescent protein with start codon deletion). The fusion gene of $\triangle \mathrm{hCAR}$ and $\triangle \mathrm{EGFP}$ was constructed by replacing the $\triangle \mathrm{hCAR}$ stop codon and the EGFP start codon with a linker sequence shown above the schematic presentation of the lentivirus vector.

was added. Ganciclovir (GCV) containing media was added $24 \mathrm{~h}$ post-infection and cells were grown in the presence of $\operatorname{GCV}(10 \mu \mathrm{g} / \mathrm{ml})$ for 5 days.

All the statistical analyses were done by using the MannWhitney test. A p-value of $<0.05$ was regarded as significant.

\section{Results}

To allow efficient adenoviral gene transfer of B cells, adenovirus vector particles need to be modified in order to recognize molecules that are present on B cell surface. As we did not have access to adenovirus modification technology, the targeting to B cells was simulated by making B cells more permissive to standard adenovirus vectors i.e. modifying these cells to express the primary attachment receptor hCAR. Since it has been observed that HF28RA cells are resistant to various non-viral gene delivery methods, such as polycation PEI (polyethyleneimine) or liposomes DOPE (1,2-Dioleyl-3phosphatidylethanolamine) and DOTAP $(N-[1-(2,3-$ dioleoyloxy)propyl]- $N, N, N$-trimethyl ammonium methylsulfate) or electroporation (data not shown), we decided to carry out the B cell modifications with lentivirus-mediated gene transfer because lentiviruses transduce a wide selection of target cells (19), and cause stable, long-term gene expression by integrating the transgene into target cell genome.

Follicular lymphoma cell line HF28RA was transduced with a lentiviral vector containing the hCAR-EGFP fusion gene, using 1.5 t.u./cell (Fig. 1) and transduction efficiency was analyzed by flow cytometry (Fig. 2A). HF28RA cells showed variable expression of hCAR-EGFP after lentivirusmediated transduction. The bright hCAR-EGFP positive cells were enriched by cell sorting (Fig. 2A). The phenotype of bright positive, sorted hCAR-EGFP cells were stable in cell culture for a month.

The cell surface expression of the hCAR-EGFP fusion protein in enriched HF28RA hCAR cells was further analyzed and the extracellular domain of hCAR was detected using anti-hCAR mAb and Tri-color conjugated secondary Ab. The results (Fig. 2B) showed that $27 \%$ of enriched HF28RA hCAR cells were double positive for hCAR-EGFP and anti-hCAR $\mathrm{mAb}$. This result demonstrated that the EGFP-tailed hCAR was properly expressed, with the correct domain accessible
A

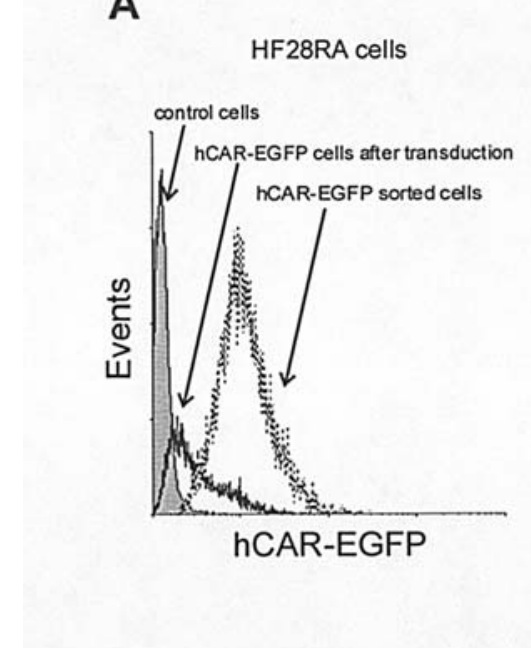

B
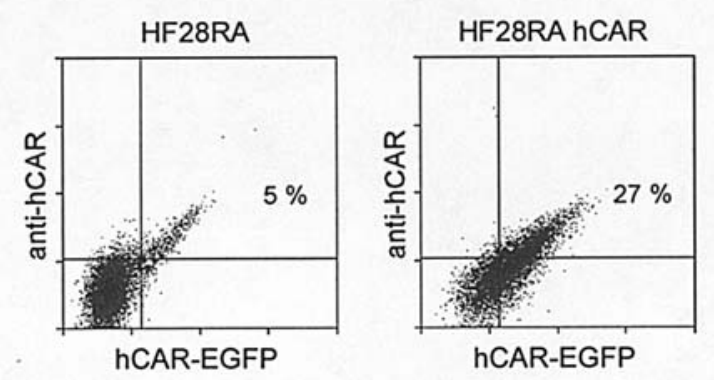

Figure 2. Enrichment of hCAR-EGFP cells by sorting and detection of hCAR-EGFP surface expression. HF28RA cell line was transduced with a lentiviral vector (1.5 t.u./cell) containing the hCAR-EGFP fusion gene, and the bright hCAR-EGFP positive cells were further enriched with cell sorting using FACS (A). The cell surface expression of hCAR-EGFP in enriched HF28RA hCAR cells was measured using FACS after cell stainings with hCAR-specific anti-hCAR mAb (RmcB, mouse anti-human monoclonal Ab) and Tri-color conjugated goat anti-mouse $\mathrm{Ab}(\mathrm{B})$.

on the cell surface. The functionality of the hCAR-EGFP fusion protein was studied by transducing the cells with AdDsRed2. The expression of DsRed2 was measured with FACS (Fig. 3A). AdDsRed2 efficiently transduced HF28RA hCAR-EGFP cells when compared to parental HF28RA cells (Fig. 3A and B). In HF28RA hCAR cells, the expression of DsRed2 was significantly higher with 1 pfu/cell [4.9 MFI (mean fluorescence intensity) $\pm 0.83 \mathrm{SEM}]$ and $10 \mathrm{pfu} /$ cell (8.9 MFI $\pm 1.70 \mathrm{SEM}$ ) than in HF28RA cells with respective $\mathrm{pfu} /$ cell values $(1.1 \mathrm{MFI} \pm 0.03 \mathrm{SEM}$ and 3.2 MFI \pm 0.32 SEM). Fluorescence microscope images of AdDsRed2infected cells after a $48 \mathrm{~h}$ incubation also supported the FACS results (Fig. 3B), showing that higher proportion of target cells were positive for red fluorescent $(675 \mathrm{~nm})$.

To test whether hCAR-EGFP could also deliver therapeutically relevant transgenes, such as HSV-TK, HF28RA hCAR cells were infected with AdTK-GFP. DNase I-treated messenger RNA representing HSV-TK sequences was detected by RT-PCR to show that HF28RA hCAR cells were efficiently transduced even with 1 pfu/cell (Fig. 4A). The delivery of HSV-TK gene was further confirmed by transducing HF28RA hCAR and parental HF28RA cells with the 
A

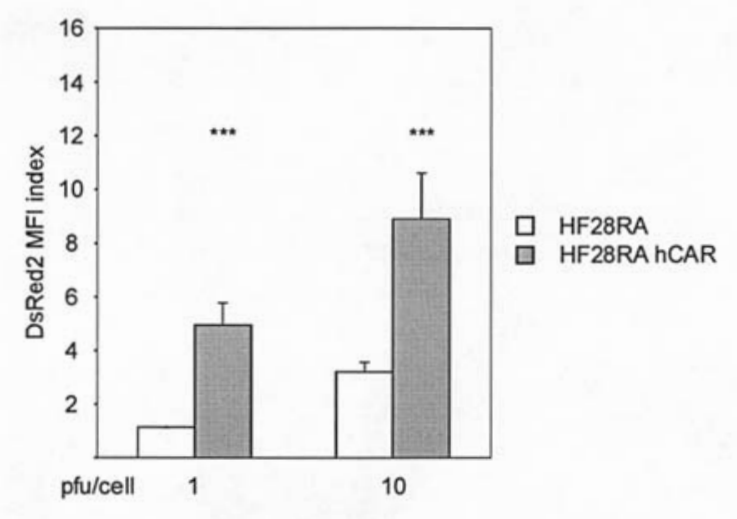

B
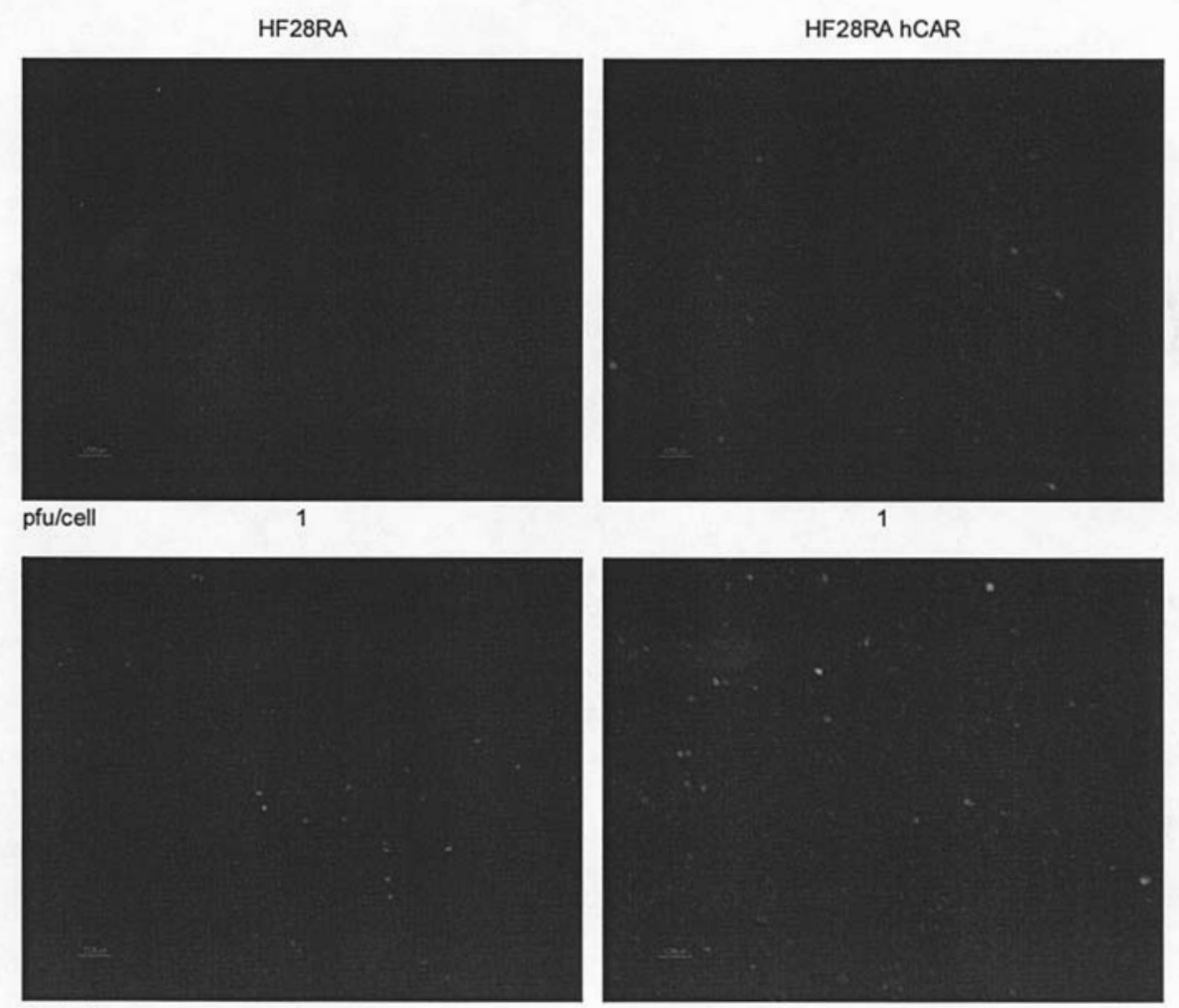

pfu/cell

10

10

Figure 3. Analysis of DsRed2 expression after cell transduction with DsRed2 adenovirus vector (AdDsRed2). Parental cells (HF28RA) and hCAR-EGFP expressing cells (HF28RA hCAR) were transduced with 1 and 10 pfu/cell using AdDsRed2. DsRed2 MFIs (mean fluorescence intensity) were detected with FACS after cell cultivation for $48 \mathrm{~h}$. The MFI index results were calculated by dividing individual MFI result (pfu/cell 1 or 10 ) with negative control MFI result (pfu/cell 0). Data are shown as mean \pm SEM of three independent experiments with triplicate samples. Statistical analyses were done by using the Mann-Whitney test. A p-value of $<0.05$ was regarded as significant (A). The HF28RA and HF28RA hCAR cells were incubated for 48 h after AdDsRed2 transduction with 1 and $10 \mathrm{pfu} / \mathrm{cell}$. The cells were further visualized with a fluorescent microscope. Data are shown as a representative example of three independent experiments (B).

AdTK-GFP vector, followed by a 5-day incubation with GCV. The cell viability after GCV treatment was measured using MTT method (Fig. 4B). In HF28RA hCAR cells, both viral doses yielded significantly $(\mathrm{p}<0.05)$ decreased cell viability when compared to parental HF28RA cells. The viability of parental HF28RA cells appeared to be virtually unaffected under conditions that destroyed about $1 / 3$ of the hCAR expressing cells. The AdTK-GFP transduction alone did not induce cellular proliferation (Fig. 4B, grey columns). In addition, the cell viability was significantly $(\mathrm{p}<0.05)$ higher compared to AdTK-GFP-transduced and GCV-treated HF28RA hCAR cells (Fig. 4B, black columns).

\section{Discussion}

It is known that hematopoietic malignancies are difficult targets for virus-mediated gene therapy due to the systemic nature of the disease (28). In addition, the efficiency and target cell specificity of vectors should be improved before systemically administered gene therapy can be fully utilized $(6,7,9,10,19,29)$. 
A

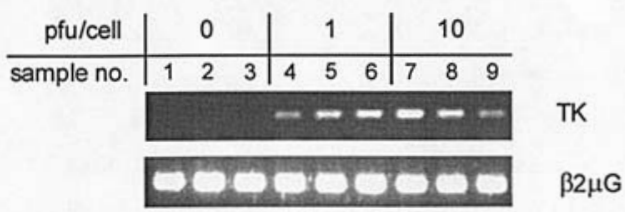

B

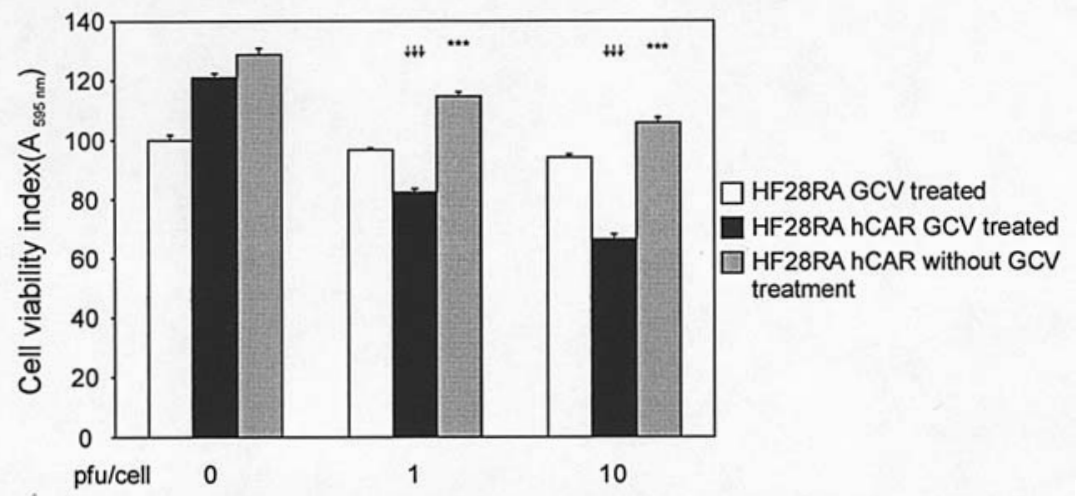

Figure 4. Analysis of TK (herpes simplex virus type I thymidine kinase) mRNA expression after transduction with the TK-GFP adenovirus vector (AdTKGFP), and the cell viability test after TK-GFP gene therapy and ganciclovir (GCV) treatment. HF28RA hCAR cells were transduced using AdTK-GFP with 0 or 1 or $10 \mathrm{pfu} / \mathrm{celll}$. Expression of TK and $\beta 2 \mu \mathrm{G}$-specific and DNase I-treated mRNA was detected by RT-PCR. Data are shown as a representative experiment with triplicate samples (A). Cell viability was tested with MTT method after cells were transduced using AdTK-GFP with 0 or 1 or 10 pfu/cell followed by 5-day incubation in the presence of $10 \mu \mathrm{g} / \mathrm{ml} \mathrm{GCV}$. Data are shown as mean \pm SEM of three independent experiments with triplicate samples. Statistical analyses were done by using the Mann-Whitney test. A p-value of $<0.05$ was regarded as significant. The cell viability decreased with statistical significance is marked with $\downarrow \downarrow \downarrow$ when compared to HF28RA cells in the presence of GCV. The cell viability changed with statistical significance is marked with *** when compared to HF28RA hCAR cells in the presence of GCV (B).

Adenoviruses have been used widely during the past years because of their high titer recombinant virus production, broad target cell tropism, capability to infect postmitotic cells and large DNA packaging capacity. In contrast to genome integrating retroviruses that can have adverse effects, such as induction of leukemia-type diseases (30), adenoviral DNA is expressed transiently from extrachromosomal elements, which is a desired feature in most forms of cancer gene therapy (12). On the other hand, immunogenicity has been one of the major obstacles in gene therapy with adenovirus vectors (31). Although adenovirus target cell tropism is known to be broad, human peripheral blood leukocytes, spleen and thymus cells do not express hCAR, which makes them resistant to adenovirusmediated infection $(17,32)$. It has also been reported that hCAR is not expressed on the cell surface of bone marrow (BM) $\mathrm{CD} 9^{+} \mathrm{B}$ cells or $\mathrm{CD}^{+}$or $\mathrm{CD}^{+} \mathrm{T}$ cells (33). Similarly, the unmodified follicular lymphoma B cells used in this study were resistant to adenovirus infection due to lack of endogenous hCAR (adenovirus attachment receptor) on the plasma membrane. In our indirect targeting model, we were able to show that originally hCAR negative non-adherent cancer cells could be efficiently infected and treated with adenovirusmediated suicide gene therapy.

In order to initiate B cell-specific gene therapy experiments, in vitro or in vivo, development of new retargeted virus vectors are required. It is known that adenovirus capsid modifications are extremely laborious. Therefore, we propose the use of a fusion protein containing a cell-specific $\mathrm{Ab}$ and adenovirus capsid-targeted protein to redirect viral vectors to B cells as described previously with ovarian cancer cells (15). We suggest that possible B cell-specific cell surface structures would be BCR, CD19 or CD20. Among these the most suitable target molecule would be BCR because it is highly B cell-specific and abundantly expressed on the B cell surface. Because BCR and serum antibodies have identical structure, the B cellspecific retargeting molecule expressed on the B cell surface should be a member of the BCR complex, such as Ig $\alpha$ and $\operatorname{Ig} ß$. Using this retargeting design, intravenously administered gene therapy might have high efficacy and endogenous adenovirus vector neutralization induced by serum Abs would be prevented. In addition to described fusion protein strategy, successful B cell-specific gene therapy model was reported using adenovirus vectors combined with bi-specific peptide recognizing both adenovirus capsid structures and CD40 receptor (34). In addition to adenovirus vector retargeting, the use of strictly B cell-specific promoterenhancer combination (VH promoter-3' enhancer) (35), would decrease severe side-effects such as by-stander cell death or tissue destruction. Furthermore, adenoviral but indirect methods could be used to treat B cell-derived malignancies, such as induction of anti-tumor immune reaction (36).

In this study, we showed indirectly that targeted adenoviruses can be used efficiently in the gene therapy of hematopoietic malignancies e.g. B cell cancers. However, in order to markedly increase the survival of patients with B cell malignancy, a new generation of targeted adenoviruses expressing strictly target cell-specific structures on the virus capsid are required. 


\section{Acknowledgements}

This study was supported by grants from The Finnish Cultural Foundation of Northern Savo, Finnish-Norwegian Medical Science Foundation, Academy of Finland and Kuopio University Hospital. We thank Pia Nissinen, Riitta Korhonen, Päivi Kivistö and Tuula Keinänen for excellent technical assistance.

\section{References}

1. Hoelzer D, Gokbuget N, Ottmann O, Pui CH, Relling MV, Appelbaum FR, van Dongen JJ and Szczepanski T: Acute lymphoblastic leukemia. Hematology pp162-192, 2002.

2. Pui CH, Schrappe M, Ribeiro RC and Niemeyer CM: Childhood and adolescent lymphoid and myeloid leukemia. Hematology pp118-145, 2004.

3. Diehl V, Stein H, Hummel M, Zollinger R and Connors JM: Hodgkin's lymphoma: biology and treatment strategies for primary, refractory, and relapsed disease. Hematology pp225247, 2003.

4. Fisher RI, Miller TP and O'Connor OA: Diffuse aggressive lymphoma. Hematology pp221-236, 2004.

5. Cantwell MJ, Sharma S, Friedmann T and Kipps TJ: Adenovirus vector infection of chronic lymphocytic leukemia B cells. Blood 88: 4676-4683, 1996.

6. Von Seggern DJ, Huang S, Fleck SK, Stevenson SC and Nemerow GR: Adenovirus vector pseudotyping in fiberexpressing cell lines: improved transduction of Epstein-Barr virus-transformed B cells. J Virol 74: 354-362, 2000.

7. White RE, Wade-Martins R and James MR: Infectious delivery of 120-kilobase genomic DNA by an epstein-barr virus amplicon vector. Mol Ther 5: 427-435, 2002.

8. Hellebrand E, Mautner J, Reisbach G, Nimmerjahn F, Hallek M, Mocikat R and Hammerschmidt W: Epstein-Barr virus vectormediated gene transfer into human $B$ cells: potential for antitumor vaccination. Gene Ther 13: 150-162, 2006.

9. Wendtner CM, Kofler DM, Theiss HD, Kurzeder C, Buhmann R, Schweighofer C, Perabo L, Danhauser-Riedl S, Baumert J, Hiddemann W, Hallek M and Buning H: Efficient gene transfer of CD40 ligand into primary B-CLL cells using recombinant adenoassociated virus (rAAV) vectors. Blood 100: 1655-1661, 2002.

10. Bovia F, Salmon P, Matthes T, Kvell K, Werner-Favre C, Nguyen TH, Barnet M, Nagy M, Leuba F, Arrighi JF, Piguet V, Trono D and Zubler RH: Efficient transduction of primary human B lymphocytes and nondividing myeloma B cells with HIV-1-derived lentiviral vectors. Blood 101: 1727-1733, 2003.

11. Quartier P, Debre M, De Blic J, De Sauverzac R, Sayegh N, Jabado N, Haddad E, Blanche S, Casanova JL, LeDeist F, Smith CI, De Saint Basile G and Fischer A: Early and prolonged intravenous immunoglobulin replacement therapy in childhood agammaglobulinemia: a retrospective survey of 31 patients. J Pediatr 134: 589-596, 1999.

12. Kovesdi I, Brough DE, Bruder JT and Wickham TJ: Adenoviral vectors for gene transfer. Curr Opin Biotechnol 8: 583-589, 1997.

13. Koizumi N, Mizuguchi H, Sakurai F, Yamaguchi T, Watanabe Y and Hayakawa T: Reduction of natural adenovirus tropism to mouse liver by fiber-shaft exchange in combination with both CAR - and alphav integrin-binding ablation. J Virol 77: 13062-13072, 2003.

14. Anonymous Assessment of Adenoviral Vector Safety and Toxicity: Report of the National Institutes of Health Recombinant DNA Advisory Committee. Hum Gene Ther 13: 3-13, 2002.

15. Hakkarainen T, Hemminki A, Pereboev AV, Barker SD, Asiedu CK, Strong TV, Kanerva A, Wahlfors J and Curiel DT: CD40 is expressed on ovarian cancer cells and can be utilized for targeting adenoviruses. Clin Cancer Res 9: 619-624, 2003.

16. Pereboev AV, Asiedu CK, Kawakami Y, Dong SS, Blackwell JL, Kashentseva EA, Triozzi PL, Aldrich WA, Thomas JM, Curiel DT and Dmitriev IP: Coxsackievirus-adenovirus receptor genetically fused to anti-human CD40 scFv enhances adenoviral transduction of dendritic cells. Gene Ther 9: 1189-1193, 2002.

17. Colin M, Renaut L, Mailly L and D'Halluin JC: Factors involved in the sensitivity of different hematopoietic cell lines to infection by subgroup $\mathrm{C}$ adenovirus: implication for gene therapy of human lymphocytic malignancies. Virology 320: 23-39, 2004.
18. Siemasko K and Clark MR: The control and facilitation of MHC class II antigen processing by the BCR. Curr Opin Immunol 13: 32-36, 2001.

19. Pellinen R, Hakkarainen T, Wahlfors T, Tulimaki K, Ketola A, Tenhunen A, Salonen T and Wahlfors J: Cancer cells as targets for lentivirus-mediated gene transfer and gene therapy. Int $\mathrm{J}$ Oncol 25: 1753-1762, 2004.

20. Matto M, Nuutinen UM, Ropponen A, Myllykangas K and Pelkonen J: CD45RA and RO isoforms have distinct effects on cytokine- and B-cell-receptor-mediated signalling in human B cells. Scand J Immunol 61: 520-528, 2005.

21. Hsu KH, Lonberg-Holm K, Alstein B and Crowell RL: A monoclonal antibody specific for the cellular receptor for the group B coxsackieviruses. J Virol 62: 1647-1652, 1988.

22. Wieland S, Dobbeling U and Rusconi S: Interference and synergism of glucocorticoid receptor and octamer factors. EMBO J 10: 2513-2521, 1991.

23. Naldini L, Blomer U, Gallay P, Ory D, Mulligan R, Gage FH, Verma IM and Trono D: In vivo gene delivery and stable transduction of nondividing cells by a lentiviral vector. Science 272: 263-267, 1996

24. Hakkarainen T, Wahlfors T, Merilainen O, Loimas S, Hemminki A and Wahlfors J: VP22 does not significantly enhance enzyme prodrug cancer gene therapy as a part of a VP22-HSVTk-GFP triple fusion construct. J Gene Med 7: 898-907, 2005.

25. Eray M, Postila V, Eeva J, Ripatti A, Karjalainen-Lindsberg ML, Knuutila S, Andersson LC and Pelkonen J: Follicular lymphoma cell lines, an in vitro model for antigenic selection and cytokinemediated growth regulation of germinal centre B cells. Scand J Immunol 57: 545-555, 2003.

26. Palu G, Cavaggioni A, Calvi P, Franchin E, Pizzato M, Boschetto R, Parolin C, Chilosi M, Ferrini S, Zanusso A and Colombo F: Gene therapy of glioblastoma multiforme via combined expression of suicide and cytokine genes: a pilot study in humans. Gene Ther 6: 330-337, 1999.

27. Bouaboula M, Legoux P, Pessegue B, Delpech B, Dumont X, Piechaczyk M, Casellas P and Shire D: Standardization of mRNA titration using a polymerase chain reaction method involving co-amplification with a multispecific internal control. J Biol Chem 267: 21830-21838, 1992.

28. Wierda WG and Kipps TJ: Gene therapy of hematologic malignancies. Semin Oncol 27: 502-511, 2000.

29. Li L, Wickham TJ and Keegan AD: Efficient transduction of murine B lymphocytes and B lymphoma lines by modified adeno-viral vectors: enhancement via targeting to FcR and heparan-containing proteins. Gene Ther 8: 938-945, 2001.

30. Hacein-Bey-Abina S, Von Kalle C, Schmidt M, LeDeist F, Wulffraat N, McIntyre E, Radford I, Villeval JL, Fraser CC, Cavazzana-Calvo $\mathrm{M}$ and Fischer A: A serious adverse event after successful gene therapy for X-linked severe combined immunodeficiency. N Engl J Med 348: 255-256, 2003.

31. Thomas CE, Ehrhardt A and Kay MA: Progress and problems with the use of viral vectors for gene therapy. Nat Rev Genet 4: 346-358, 2003.

32. Tomko RP, Xu R and Philipson L: HCAR and MCAR: the human and mouse cellular receptors for subgroup $\mathrm{C}$ adenoviruses and group B coxsackieviruses. Proc Natl Acad Sci USA 94: 3352-3356, 1997.

33. Rebel VI, Hartnett S, Denham J, Chan M, Finberg R and Sieff CA: Maturation and lineage-specific expression of the coxsackie and adenovirus receptor in hematopoietic cells. Stem Cells 18: 176-182, 2000.

34. Richards JL, Abend JR, Miller ML, Chakraborty-Sett S, Dewhurst $S$ and Whetter LE: A peptide containing a novel FPGN CD40-binding sequence enhances adenoviral infection of murine and human dendritic cells. Eur J Biochem 270: 2287-2294, 2003.

35. Pettersson S, Cook GP, Bruggemann M, Williams GT and Neuberger MS: A second B cell-specific enhancer 3' of the immunoglobulin heavy-chain locus. Nature 344: 165-168, 1990 .

36. Takahashi S, Yotnda P, Rousseau RF, Mei Z, Smith S, Rill D, Younes A and Brenner MK: Transgenic expression of CD40L and interleukin-2 induces an autologous antitumor immune response in patients with non-Hodgkin's lymphoma. Cancer Gene Ther 8: 378-387, 2001. 